Elsevier

JAD 00412

\title{
Circadian Symptom Fluctuations in People with Anxiety Disorders
}

\author{
Oliver G. Cameron, Myung A. Lee, Joan Kotun and Kathleen M. McPhee \\ Department of Psychiary, University of Michigan, Ann Arbor, MI 48109 (U.S.A.) \\ (Received 1 August, 1986) \\ (Accepted 8 October, 1986)
}

\begin{abstract}
Summary
Circadian rhythm abnormalities have been demonstrated in people with depression, including a tendency toward maximal symptom severity in the morning. Although a few studies have suggested that symptoms in people with anxiety are worse later in the day, no detailed study of this observation has been reported. In 86 patients with anxiety disorders (63 with panic disorder or agoraphobia with panic attacks), anxiety symptoms tended to be more severe in the afternoon or evening than in the morning, with no abnormalities of heart rate or oral temperature. This is the first systematic demonstration of a circadian fluctuation of mood in any disorder other than depression.
\end{abstract}

Key words: Circadian rhythm - Symptom fluctuations - Anxiety disorders

\section{Introduction}

Abnormal circadian patterns have been documented in people with affective disorders, including a tendency for early morning awakening and maximal severity of depression in the morning; however, patients with anxiety or mixed depression/anxiety report less early morning waking and a tendency for symptoms to be worse later in the day (Kiloh and Garside 1963; Mendels and Cochrane 1968; Roth et al. 1972; Mathew et al. 1982; Wehr and Goodwin 1983; Mullaney 1984;

Send all correspondence and reprint requests to: Oliver $G$. Cameron, M.D., Ph.D., Department of Psychiatry, University of Michigan Medical School, 1500 E. Medical Center Drive, Ann Arbor, MI 48109, U.S.A.
Faravelli et al. 1985; Zerssen et al. 1985); early insomnia (at time of retiring) is common in both patient groups. Anxious individuals also have other sleep abnormalities which differentiate them from depressives (Reynolds et al. 1983; Rosa et al. 1983; Uhde et al. 1984), including a tendency to go to bed later and wake later (Stonehill et al. 1976). A single case of a 6-9 h phase-advance in peak body temperature associated with exacerhations of an anxiety disorder has been reported (Crawford 1979). In animals, conditionability of 'anxiety' as represented by the 'conditioned emotional response' (CER) fluctuates in a circadian fashion (Stroebel 1967). Hormonal reactivity to stress also has a circadian variation in animals (Dunn et al. 1972; McCarty et al. 1981; Kant et al. 1986); however, resting hormone levels across 
$24 \mathrm{~h}$ in people with panic anxiety appear to be normal (Cameron et al. 1986). Despite these prior findings, no systematic study of potential circadian fluctuations of anxiety in people with clinical anxiety disorders has appeared; that is the purpose of this investigation.

\section{Method}

Three experiments were performed. In the first study, at the time of diagnostic evaluation, 63 patients retrospectively rated their average anxiety level at five different times of day ('early morning', 'late morning', 'mid-afternoon', 'early evening', and 'late evening') on a 6-point scale ('none', 'very-mild', 'mild', 'moderate', 'severe', and 'very severe') for a 'good day', an 'average day', and a 'bad day' for the previous several months. Forty of the patients had DSM-III-defined (Task Force on Nomenclature and Statistics 1980) panic attacks (16 with panic disorder and 24 with agoraphobia with panic attacks; 38 females; mean age of all 40 subjects $=37$ years); 23 had other DSM-III-defined anxiety disorders (four with generalized anxiety, three with agoraphobia without panic, three social phobics, six simple phobics, five with obsessive-compulsive disorder, and two with atypical symptoms; 15 female; mean age of all 23 subjects $=33$ years). All patients who reported panic attacks also rated the frequency of attacks which woke them from sleep. No patients in any of the three studies was in a depressive episode at the time of evaluation, but some did describe dysphoric mood. Therefore, a subset of these patients completed the SCL-9OR symptom checklist which was used to compare level of depressive symptoms to published norms. All diagnoses in all three studies were made by an experienced clinician with a semi-structured interview.

Because the first study was retrospective, two further prospective studies involving people with DSM-III-defined panic attacks were performed. In the first, 11 patients (eight with panic disorder, three with agoraphobia with panic attacks; nine female; mean age for all patients $=35$ years) and six normal subjects (four female; mean age of all $=32$ years) rated their anxiety level at five times of day $(07.00,11.00,15.00,19.00$, and 23.00 h) on a 10-point scale ('none' to 'most ever') for one week; radial pulse and oral temperature were also measured each time, and time of sleep and waking were recorded. Subjects were instructed to sit or lie down for at least $10 \mathrm{~min}$ before these measurements, and to avoid strenuous exercise for at least $30 \mathrm{~min}$. Patients and normal subjects had approximately equal average daily exercise levels.

In the second prospective study, 12 patients (six with panic disorder and six with agoraphobia with panic attacks; nine female; mean age of all $12=32$ years) recorded the time of onset and severity (same 10-point scale as the second experiment) of all panic attacks for 7-10 days. For data analysis, the day was divided into five $3.5 \mathrm{~h}$ periods similar to the other experiments (wake-up to $10.00 \mathrm{~h}, 10.00-13.30 \mathrm{~h}, 13.30-17.00 \mathrm{~h}, 17.00-20.30$ $\mathrm{h}$, and $20.30 \mathrm{~h}$ to sleep), and the recorded times of attack onset were assigned to one of these five bins in order to generate frequency counts. All subjects were informed of the purpose of the studies. All statistical results are reported for two-tailed tests.

\section{Results}

The results of the first experiment are presented in Table 1. No differences in symptom

\section{TABLE 1}

ANXIETY SCORES FOR ALL PATIENTS, AND FOR PATIENTS WITH PANIC ATTACKS

Scores are mean \pm standard deviation at five different times of day for all patients, and for patients with panic attacks only. Scale is described in the text.

\begin{tabular}{lccc}
\hline & Good day & Average day & Bad day \\
\hline All patients $(n=63)$ & & \\
Early a.m. & $2.21 \pm 1.36$ & $2.97 \pm 1.66$ & $3.94 \pm 1.57$ \\
Late a.m. & $2.05 \pm 1.08$ & $3.10 \pm 1.29$ & $3.90 \pm 1.39$ \\
Mid-afternoon & $2.33 \pm 1.12$ & $3.44 \pm 1.25$ & $4.32 \pm 1.27$ \\
Early p.m. & $2.38 \pm 1.13$ & $3.44 \pm 1.27$ & $4.30 \pm 1.32$ \\
Late p.m. & $2.14 \pm 1.15$ & $3.24 \pm 1.28$ & $4.32 \pm 1.26$ \\
Patients with panic attacks $(n=40)$ & \\
Early a.m. & $2.30 \pm 1.36$ & $3.15 \pm 1.64$ & $4.18 \pm 1.45$ \\
Late a.m. & $2.08 \pm 1.00$ & $3.25 \pm 1.30$ & $4.08 \pm 1.38$ \\
Mid-afternoon & $2.42 \pm 0.98$ & $3.45 \pm 1.22$ & $4.38 \pm 1.23$ \\
Early p.m. & $2.55 \pm 1.08$ & $3.60 \pm 1.30$ & $4.35 \pm 1.33$ \\
Late p.m. & $2.25 \pm 1.13$ & $3.35 \pm 1.29$ & $4.25 \pm 1.35$ \\
\hline
\end{tabular}


severity or pattern was observed for panic patients versus agoraphobics. A statistically significant fluctuation in severity of anxiety for all patients $(n=63)$ throughout the day was observed (repeated measures analysis of variance, $F=2.81$, $d f=4,248, \quad P<0.05$ after adjustments for repeated measures - Greenhaus-Geisser or HuynhFeldt). There was also a highly statistically significant difference between the 'good', 'average', and 'bad' days $(F=171.1, d f=2,124, P<0.0001)$. When only patients with panic attacks were included $(n=40)$, the severity level was slightly higher while the pattern through the day was very similar. However, only a weak trend toward significance was observed $(F=1.17, d f=4,156, P$ $=0.32$ ). For all patients, the lowest level was 'early morning' or 'late morning' and the highest was 'mid-afternoon' or 'early evening'. Approximately $60 \%$ of the 63 patients rated the afternoon/evening as worse than the morning. $48 \%$ of the patients with panic attacks reported that attacks sometimes awoke them from sleep; for these patients, approximately $14 \%$ of the at tacks occurred during sleep, and the maximum was $50 \%$ for one patient. Finally, 21 patients completed the SCL-90R (16 with panic attacks); in comparison to published norms for normal subjects (Derogatis 1977), these patients were at approximately the 65 th percentile - i.e., one-third of normals describe dysphoric mood at least as severe as these patients.

The results of the anxiety ratings from the second experiment are presented in Fig. 1. The overall average anxiety severity across all five times was 3.41 of a maximum possible 10 for the patients and 1.31 for the normal subjects $(t=2.33$, $d f=16, P<0.05$, unpaired $t$-test); this difference is substantial when considering that 'most ever' anxiety is greater for anxious patients than for normal subjects. For normal subjects there was no observable anxiety fluctuation through the day. For patients the overall repeated measures analysis of variance was not significant $(F=2.06, d f=$ $4,40, P=0.20$ ). However, the results of the first experiment provide an a priori hypothesis for specific testing: The anxiety level in patients will be higher in the afternoon and evening than in the morning. This was confirmed; the anxiety level was lowest at $07.00 \mathrm{~h}$ and significantly higher than

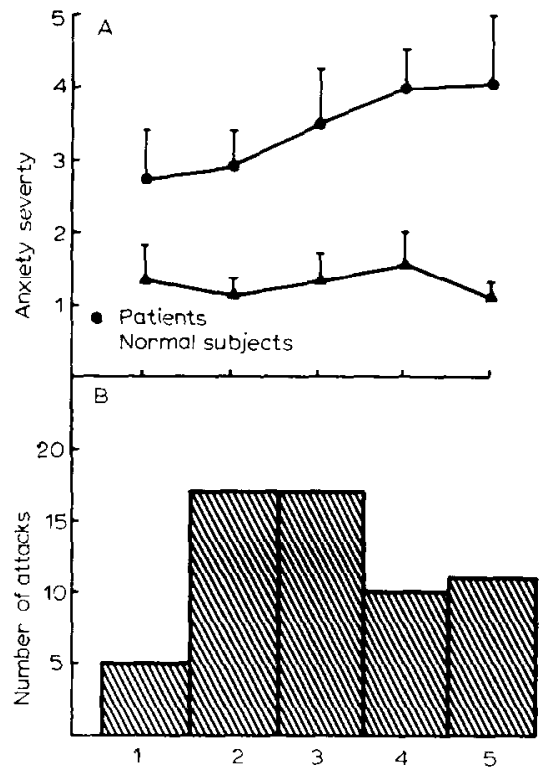

Fig. 1. Panel $A$ (Experiment 2): Concurrent anxiety severity ratings (mean $\pm S E M$ ) (from $0=$ 'none' to $10=$ 'most ever') for 11 anxiety patients with panic attacks and six normal subjects. Times of rating were: $1=07.00 \mathrm{~h}, 2=11.00 \mathrm{~h}, 3=15.00 \mathrm{~h}$, $4=19.00 \mathrm{~h}$, and $5=23.00 \mathrm{~h}$. A fluctuation was observed for patients but not normal controls; patients also had a significantly higher overall anxiety level. Panel $B$ (Experiment 3): Frequency count of time of onset of 60 panic attacks in 12 anxiety patients. Times of onset are: $1=$ wake-up to $10.00 \mathrm{~h}$, $2=10.00-13.30 \mathrm{~h}, 3=13.30-17.00 \mathrm{~h}, 4=17.00-20.30 \mathrm{~h}$, and $5=20.30 \mathrm{~h}$ to sleep. A trend for the frequency to be different from equal distribution was observed.

07.00 at 15.00 and $19.00 \mathrm{~h}(t=2.98$ and 2.48 , $d f=9$ for both, $P<0.05$ for both, paired $t$-tests) with a trend at $23.00 \mathrm{~h}(t=2.19, d f=9, P=0.07)$. The mean levels at 19.00 and $23.00 \mathrm{~h}$ approached $150 \%$ of $07.00 \mathrm{~h}$ level, and eight of the 11 patients rated their anxiety as worse in the afternoon or evening versus the morning.

The physiological measures in this experiment did not show differences between patients and normal subjects. The overall average pulse rates were very similar for the two groups ( 76.4 versus 75.9 beats per minute); the oral body temperature was non-significantly lower in the patients ( 36.5 versus $36.8^{\circ} \mathrm{C}$ ). Temperature showed a fluctuation through the day, with a peak between 15.00 and $19.00 \mathrm{~h}$ for both groups while a fluctuation in pulse rate was observed only for patients with a 
peak at $15.00 \mathrm{~h}$. Patients and normal subjects reported going to bed at approximately the same time $(23.30 \mathrm{~h})$, but patients reported waking significantly later than normals ( 07.00 versus $08.10 \mathrm{~h})$ ( $t=2.37, d f=16, P<0.05$, unpaired $t$-test).

The results of the third experiment are also presented in Fig. 1. The average number of attacks observed was five per patient; the range was 2-12. There was a trend for the distribution of times of attack onset to be different from equal probability at the five times studied $\left(\chi^{2}=8.67, d f=4, P=\right.$ 0.13 ). The median time of onset of panic attacks was approximately $15.00 \mathrm{~h}$ with less than $10 \%$ of the attacks occurring before $10.00 \mathrm{~h}$. There was also a non-significant tendency for attacks occurring between 10.00 and $20.30 \mathrm{~h}$ to be more severe than at the other times.

\section{Discussion}

The results of these three studies indicate that, unlike melancholic depression, people with anxiety disorders tend to experience increased symptoms later in the day; median time of onset of panic attacks was mid-afternoon, and overall symptom severity was worse in the late afternoon or evening. Although the fluctuation through the day for people with panic attacks was relatively small, the consistency of the pattern across three separate studies with 63 panic patients supports its validity. Furthermore, these results are in agreement with the prior studies of anxiety listed above. Interestingly, there is some suggestion that, unlike these anxious patients, normal subjects in this age range have a tendency to report feeling 'worse' in the morning rather than the evening (Abe and Suzuki 1985). Further, the circadian effect was more apparent when anxious patients without panic attacks were included; further research with homogeneous groups and larger numbers of patients are needed to evaluate the possibility that anxiety symptoms other than panic attacks also show circadian variation.

Two prior studies have commented on circadian variations of panic attacks observed while studying other aspects of panic. Uhde et al. (1985) stated that there was a "lack of any discernible rhythm' in the panic attacks they studied, but they did not present any primary data. Taylor et al.
(1986) also felt that 'attacks occurred with apparent random distribution during the day..., but an examination of the actual distribution of the 41 attacks they observed indicated an increase in frequency between 13.30 and $20.30 \mathrm{~h} ; 20$ of the attacks (49\%) occurred in this $7 \mathrm{~h}$ period, similar to the results of the present research.

Results of physiological measurements are in partial agreement with prior studies. The patients in the second experiment reported waking later than the normal subjects; however, situational factors cannot be excluded, such as the possibility that patients experienced some insomnia but slept approximately the same duration. Oral temperature was slightly lower in patients, but no phase shift was observed; more frequent measurements with a larger sample might demonstrate phase differences. Moreover, any temperature difference might indicate not lower core body temperature, but only a tendency of anxious individuals to hyperventilate, which could in turn reduce oral measurements. Finally, although acute anxiety is often associated with heart rate elevations, similar to the results of this study increases in heart rate are often not observed in people with anxiety disorders when acute anxiety is not prominent (Freedman et al. 1985).

The mechanism controlling the observed fluctuation has not been determined; either physiological and/or environmental variables might be involved. For example, MHPG (3-methoxy-4-hydroxyphenethylene glycol), a metabolite of central and peripheral nervous system catecholamines which has been linked with anxiety (Uhde et al 1982; Charney et al. 1983, 1984; Ko et al. 1983; Ballenger 1984; Sheehan et al. 1984), has a circadian fluctuation with a peak at approximately the same time as the peak time of anxiety in this study (Wehr et al. 1980; DeMet et al. 1982; Giedke et al. 1982). On the other hand, some patients in this study who were asked to rate their most 'stressful' time of day, indicated the mid-afternoon (although they rated the evening as low stress and not the morning). Thus, either increased anxiety symptoms may have led to increased stress ratings, or an increase of environmentally stressful circumstances may have contributed to the increased anxiety levels at these times. Further research will be necessary to determine the mecha- 
nism of the observed anxiety fluctuations. In the meantime, this investigation represents the only systematic demonstration that people with primary anxiety disorders experience a circadian fluctuation of their anxiety symptoms, with a peak at a different time from that seen for depressive symptoms in melancholic depression. Evaluation of time of day of peak symptoms may provide a useful clinical 'marker' to differentiate anxiety disorders from depression.

\section{References}

Abe, K. and Suzuki, T., Age trends in early awakening and feeling worse in the morning than in the evening in apparently normal people, J. Nerv. Ment. Dis., 173 (1985) 495-498.

Ballenger, J.C., Peterson, G.A., Laraia, M., Hucek, A., Lake, C.R., Iverson, D., Cox, D.J., Trockman, C., Shipe, J.R. and Wilkinson, C., A study of plasma catecholamines in agoraphobia and the relationship of serum tricyclic levels to treatment response. In: J.C. Ballenger (Ed.), Biology of Agoraphobia, American Psychiatric Press, Washington, DC, 1984, pp. 27-63.

Cameron, O.G., Lee, M.A., Curtis, G.C. and McCann D.S., Endocrine and physiological changes during 'spontaneous' panic attacks, Psychoneuroendocrinology, (1987) in press.

Charney, D.S, Heninger, G.R and Redmond, D.E, Yohimbine induced anxiety and increased noradrenergic function in humans: effects of diazepam and clonidine, Life Sci., 33 (1983) 19-29.

Charney, D.S., Heninger, G.R. and Redmond, D.E., Noradrenergic function in panic anxiety: effects of yohimbine in healthy subjects and patients with agoraphobia and panic disorder, Arch. Gen. Psychiatry, 41 (1984) 751-763.

Crawford, J.P., Endogenous anxiety and circadian rhythms, Br. Med. J., 1 (1979) 662.

DeMet, E.M., Halaris, A.E., Gwirtsman, H.E., Revo, R.M. and Becker, P.I., Effects of desipramine on diurnal rhythms of plasma 3-methoxy-4-hydroxyphenylglycol, Psychopharmacol. Bull., 18 (1982) 221-223.

Derogatis, L.R., SCL-90-R: Administration, Scoring and Procedures Manual I, Johns Hopkins University, Clinical Psychometrics Research Unit, Baltimore, MD, 1977.

Dunn, J., Scheveng, L. and Millet, P., Circadian variation in stress-evoked increases in plasma corticosterone, Am. J. Physiol., 223 (1972) 402-406.

Faravelli, C., LaMalfa, G. and Romano. S., Circadian rhythm in primary affective disorder, Compr. Psychiatry, 26 (1985) 364-369.

Freedman, P.R., Ianni, P., Ettedgui, E. and Puthezhath, N., Ambulatory monitoring of panic disorder, Arch. Gen. Psychiatry, 42 (1985) 244-248.

Giedke, A., Gaertner, H.J. and Mahal, A., Diurnal variation of urinary MHPG in unipolar and bipolar depressives, Acta Psychiatr. Scand., 66 (1982) 243-253.
Kant, G.J., Mougey, E.H. and Meyerhoff, J.L., Diurnal variation in neuroendocrine response to stress in rats: plasma $\Lambda \mathrm{CTH}, \boldsymbol{\beta}$-endorphin, $\beta$-LPH, corticosterone, prolactin and pituitary cyclic AMP responses, Neuroendocrinology, 43 (1986) 383-390.

Kiloh, L.G. and Garside, R.F., The independence of neurotic depression and endogenous depression, Br. J. Psychiatry, 109 (1963) 451-463.

Ko. G.N., Elsworth, J.D., Roth, R.H., Rifkin, B.G., Leigh, H. and Redmond, E., Panic-induced elevation of plasma MHPG levels in phobic-anxious patients, Arch. Gen. Psychiatry, 40 (1983) 425-430.

Mathew, R.J., Swihart, A.A. and Weinman, M.L., Vegetative symptoms in anxiety and depression, Br. J. Psychiatry, 141 (1982) 162-165.

McCarty, R., Kvetnansky, R. and Kopin, I.J., Plasma catecholamines in rats: daily variations in basal levels and increments in response to stress, Physiol. Behav., 26 (1981) 27-31.

Mendels, J. and Cochrane, C., The nosology of depression: the endogenous-reactive concept, Am. J. Psychiatry, 124 (Suppl.) (1968) 1-11.

Mullaney, J.A., The relationship between anxiety and depression. J. Affect. Disord., 7 (1984) 139-148.

Reynolds, C.F., Shaw, D.H., Newton, T.F., Coble, P.A. and Kupfer, D.J., EEG sleep in outpatients with generalized anxiety, a preliminary comparison with depressed outpatients, Psychiatry Res., 8 (1983) 81-89.

Rosa, R.R., Bonnet, M.H. and Kramer, M., The relationships of sleep and anxiety in anxious subjects, Biol. Psychol., 16 (1983) 119-126.

Roth, M., Gurney, C., Garside, R.F. and Kerr, T.A., Studies in the classification of affective disorders: the relationship between anxiety states and depressive illnesses - I, Br. J. Psychiatry, 121 (1972) 147-161.

Sheehan, D.V., Coleman, J.H., Greenblatt, D.J., Jones, K.J., Levine, P.H., Orsalak, P.J., Peterson, M., Schildkraut, J., Urogara, E. and Watkins. D., Some biochemical correlates of panic attacks with agoraphobia and their response to a new treatment. J. Clin. Psychopharmacol., 4 (1984) 66-75.

Stonchill, E., Crisp, A.H. and Koval, J., The relationship of reported sleep characteristics to psychiatric diagnosis and mood, Br. J. Med. Psychol., 49 (1976) 381-391.

Stroebel, C.F., Behavioral aspects of circadian rhythms. In: J. Zubin and H.F. Hunt (Eds.), Comparative Psychopathology: Animal and Human. Grune and Stratton, New York, 1967 , pp. 158-172

Task Force on Nomenclature and Statistics, Diagnostic and Statistical Mantual of Mental Disorders, 3rd edn. (DSM-III), American Psychiatric Press, Washington, DC, 1980.

Taylor, C.B., Sheikh, J., Agras, W.S., Roth, W.T., Margraf, J., Ehlers, A., Maddock, R.J. and Gossard, D., Ambulatory heart rate changes in patients with panic attacks, Am. J. Psychiatry, 143 (1986) 478-482.

Uhde, T.W., Siever, L.J., Post, R.M., Jimerson, D.C.. Boulenger, J.-P. and Buchsbaum, M.S., The relationship of plasma-free MHPG to anxiety and psychophysical pain in normal volunteers, Psychopharmacol. Bull., 18 (1982) 129-132. 
Uhde, T.W., Roy-Byrne, P., Gillin, C., Mendelson, M.B., Boulenger, J.-P., Vittone, B.J. and Post, R.M., The sleep of patients with panic disorder: a preliminary report, Psychiatry Res., 12 (1984) 251-259.

Uhde, T.W., Roy-Byrne, P.P., Vittone, B.J., Boulenger, J.-P. and Post, R.M., Phenomenology and neurobiology of panic disorder. In: A.H. Tuma and J. Maser (Eds.), Anxiety and the Anxiety Disorders. Lawrence Erlbaum Associates Publishers, Hillsdale, NJ, 1985, pp. 557-576.

Wehr, T.A. and Goodwin, F.K., Circadian Rhythms in Psychiatry, Boxwood Press, Pacific Grove. CA, 1983.
Wehr, T.A., Muscettola, G. and Goodwin, E.K., Urinary 3methoxy-4-hydroxyphenylglycol circadian rhythm, Arch. Gen. Psychiatry, 37 (1980) 257-263.

Wehr, T.A., Sack, D.A., Duncan, W.C., Mendelson, W.B., Rosenthal, N.E., Gillin, J.C. and Goodwin, F.K., Sleep and circadian rhythms in affective patients isolated from external time cues, Psychiatry Res., 15 (1985) 327-339.

Zerssen, D.V., Barthelmes, H., Derlich, G., Doerr, P., Emrich. H.M., von Lendern, L., Lund, R, and Perke, K.M., Circadian rhythms in endogenous depression, Psychiatry Res., 16 (1985) 51-63. 